\title{
la Cooperación Estatal Frente a los problemas Intermésticos. La Amenaza Transnacional Criminal en Latinoamérica y el Papel de las Policías
}

JUAN APARICIO BARRERA

Policía Nacional de Colombia - Bogotá, D. C., Colombia

$$
\approx
$$

\section{RESUMEN}

El principal problema interméstico de Latinoamérica corresponde a la emergencia del crimen con carácter transnacional (actores no estatales). Para ilustrar el problema y los actores se tratan los flagelos del narcotráfico, tráfico de medicamentos falsos, trata de personas, tráfico de migrantes, cibercriminalidad, delitos contra el medioambiente, tráfico de armas de fuego, minería ilegal, hurto de celulares, falsificación de moneda, contrabando, violación de los derechos autor, hurto de automotores, hurto al patrimonio cultural, corrupción y lavado de activos. Metodología. Ejercicio descriptivo apoyado en artículos científicos sobre el tema y datos estadísticos policiales entre los años 2003-2012; es un trabajo exploratorio y de reflexión. Resultados. Se indica que para hacer frente a estos retos los Estados recurren a la cooperación, en especial de las instituciones policiales, y se muestra el caso colombiano.

Palabras Clave: Seguridad. Delitos transnacionales. Cooperación. Policía. Interméstico (fuente: Tesauro de política criminal latinoamericana - Ilanud).

\section{INTRODUCCIÓN}

Este artículo ubica el crimen transnacional en Latinoamérica, generado por actores no estatales, como la principal problemática emergente de los Estados y sus ciudadanos. Para establecer el nivel de afectación del crimen transnacional en Latinoamérica se realizó la descripción de 16 fenómenos, que se pueden comprender como criminalidad compleja (SAÍN, 2010). Estos tienen como característica que se cometen por organizaciones delincuenciales (CONVENCIÓN DE PALERMO, 2000), y que para su materialización requieren la circulación (victimarios, víctimas y bienes) por varios países. 
Parala recolección dela información se recurrió a textos especializados y a la normatividad internacional sobre la delincuencia organizada, y se consultaron datos del Sistema Estadístico Delincuencial, Contravencional y Operativo de la Policía Nacional (Siedco) entre los años 2003 y 2012.

Luego de describir estos fenómenos se señalan las acciones que, desde la cooperación, han tomado los Estados en Latinoamérica para hacer frente a estas amenazas comunes, entre ellas la cooperación internacional desde las policías: i) acuerdos bilaterales; ii) misiones de paz, y iii) los organismos internacionales de policía (Interpol -ONU- y Ameripol -OEA-).

Estos fenómenos y acciones abren una nueva discusión de la política exterior frente a problemas de carácter intermésticos, y el papel de las cancillerías con relación a la actividad internacional creciente de los ministerios de Gobierno, Interior, Defensa, Seguridad, Comercio, etc., o el papel más destacado de las instituciones policiales, los paradigmas del derecho internacional y los límites de la transnacionalización del derecho penal (convenciones con carácter vinculante para los Estados que las ratifican, cortes internacionales, grupos de abogados transnacionales), entre otras instituciones, funciones o actuaciones que antes solo se consideraban del ámbito interno de los Estados. Estos elementos permiten entender la cooperación internacional, en las nuevas dinámicas, bajo la lógica sujetosujeto, no como una relación objeto-sujeto -las potencias imponen su agenda-o como un asunto de caridad -los más ricos dan a los más pobres-, sino como una respuesta realista entre los Estados a problemas comunes, que se pueden enmarcar bajo el concepto de realismo cooperativo.

En todo caso, el crimen transnacional y las labores de las policías son poco o nada tratados por los expertos de las relaciones internacionales y de la ciencia política, lo cual es una oportunidad para ampliar el campo de estudios en relaciones internacionales y sobre la globalización.

\section{LOS PROBLEMAS DE LA DELINCUENCIA ORGANIZADA}

El crimen transnacional es el lado negativo u oscura de la globalización (ROCHA, 2011, p. 17; HEINE \& THAKUR, 2011)². En

1 Según Ferrajoli (2006, p. 301): "Uno de los efectos perversos de la globalización es sin duda el desarrollo, con dimensiones que no tienen precedente, de una criminalidad internacional, a su vez 
Latinoamérica, en las últimas décadas, la delincuencia organizada adquirió un carácter transnacional para ciertos fenómenos delictivos, lo cual afecta tanto a los Estados como a sus ciudadanos. En otras palabras, la delincuencia organizada como actor no estatal (ROJAS, 2000) es un problema interno y externo de los Estados (RIORDAN, 2005), o en palabras de Manning (1977), un problema interméstico.

El delito transnacional es uno de los problemas del mundo contemporáneo que se pueden interpretar como un efecto de la movilidad de personas, dinero, ideas y mercancías (CASEY, 2010, p. 393). Estas contradicciones de los procesos de globalización (o mundialización) han repercutido en la transformación de las labores de policía, ya que al ser los delitos de carácter transnacional, también las actuaciones de las policías adquieren el mismo sentido.

Aunque algunos de los crímenes transnacionales llevan siglos de incidencia, su ascenso, visibilización o emergencia se presentó en la era de la globalización, luego del debilitamiento, en la pos-Guerra Fría, de los grupos subversivos, la reconfiguración criminal, en especial de las organizaciones del narcotráfico, y la búsqueda de mejores mercados por las organizaciones delincuenciales.

Es una problemática seria y compleja. El crimen ocupa los encabezados de las noticias en todo el mundo y es una de las principales preocupaciones dentro de las encuestas que aquejan a los ciudadanos en Latinoamérica; de hecho, frente a los distintos fenómenos, los ciudadanos pueden ser víctimas sin saberlo (consumo de medicamentos falsos, alimentos adulterados o falsos y falsedad marcaria) o ser conscientes del delito (compras de CD, DVD o software piratas); en todo caso, son fenómenos en que todos los ciudadanos resultan afectados (e. g., la contaminación del aire y afluentes de agua por desechos). De igual forma, los victimarios pueden ser de cualquier nacionalidad ${ }^{2}$, y en muchas oportunidades no requieren desplazarse de su lugar de domicilio.

global. Se trata de una criminalidad 'global' o 'globalizada', en el mismo sentido en que hablamos de globalización de la economía: es decir, en el sentido de que la misma, por los actos realizados o por los sujetos implicados, no se desarrolla solamente en un único país o territorio estatal, sino a la par de las actividades económicas de las grandes corporations multinacionales, a nivel transnacional o incluso planetario".

2 E. g.: para finales del 2011, según el Instituto Nacional Penitenciario y Carcelario (Inpec), había 791 extranjeros presos en cárceles colombianas $(0,94 \%$ del total de la población carcelaria); de estos el $22,88 \%$ son venezolanos, y el 20,99 \%, españoles. Del total de extranjeros, el 35,5\% se encontraban privados de la libertad por el delito de tráfico, fabricación o porte de estupefacientes. 
El impacto de las organizaciones delincuenciales se puede evidenciar en su incidencia en las altas tasas de homicidios, que convierten a la subregión en una de las más violentas del mundo (UNODC, 2011), la alta corrupción en las esferas públicas y privadas (TRANSPARENCY INTERNATIONAL, 2012), niveles elevados en las encuestas de percepción de inseguridad, y otros datos que en ausencia de estadísticas delictivas oficiales pasan inadvertidos para la opinión pública, como el hurto de vehículos, celulares, entre otros. Estas son las razones por las cuales la población y los gobiernos han identificado la seguridad como una de sus necesidades prioritarias y como uno de los puntos ineludibles en las políticas públicas de los gobiernos. Esta situación ha repercutido en el protagonismo del papel de las policías (RUIZ, ILLERA \& MANRIQUE, 2006) para la contención de la criminalidad.

En resumen, el crimen transnacional representa un triple desafió para los Estados, ya que genera: percepciones de seguridad altas por parte de la población; elevadas tasas de criminalidad, y desborde de la capacidad represiva del Estado por la actuación de las organizaciones delincuenciales.

\section{HACIA UN REALISMO COOPERATIVo}

Aún no se ha estudiado con la suficiente amplitud el impacto del crimen transnacional, sus características y la respuesta desde la política exterior de los Estados del continente, quizá por la misma novedad del fenómeno. Lo presenciado en las últimas décadas en Latinoamérica, frente al problema del crimen organizado transnacional, es que las propuestas de respuestas y de agenda en la política pública nacional e internacional son multilaterales de cooperación ${ }^{3}, y$ provienen más de las instituciones públicas de policía o de los ministerios del Interior, de Seguridad o Defensa ${ }^{4}$, que de las cancillerías (RIORDAN, 2005); en otras palabras, las cancillerías tienen

3 Esta última situación, es decir, la cooperación entre Estados, está en contravía de lo expresado por Riordan (2005) frente a Estados fallidos en Latinoamérica o al vaciamiento de su contenido, bajo el supuesto de que antes "...el Estado nación tradicional se definía por una serie de poderes o responsabilidades: politica exterior; politica de defensa; politica monetaria; control de las fronteras; policia interior, y recaudación de impuestos...", y ahora no. El mismo Riordan (2005) indica que las cuestiones importantes de seguridad internacional siguen siendo resorte de los Estados-nación. El cambio sustancial con la globalización es el paso de la guerra entre ejércitos (amenaza bélica) a la cooperación entre policías para hacer frente a problemas comunes.

4 Dada esta prioridad, la agenda de la política exterior colombiana es llevada principalmente por el Ministerio de Defensa, aunque buena parte de ella está "narcotizada", por lo que los críticos han pedido "desnarcotizarla", sobre todo con los EE. UU. 
un espacio reducido en estos temas frente a la creciente participación de otras agencias (RUSSELL, 1990).

Cada vez es más creciente, en la última década, el abordaje en las cumbres (presidenciales y ministeriales), acuerdos bilaterales, memorandos de entendimiento, convenios, pactos, etc., de temas de seguridad y las formas de hacer frente al crimen transnacional ${ }^{5}$.

Estos problemas y respuestas comunes de los Estados del continente sugieren un nuevo tipo de relaciones entre ellos, que podemos enmarcarlo dentro del concepto de realismo cooperativo. Este debe entenderse en la voluntad de los Estados para dar cuenta a problemas comunes, que ningún Estado por sí solo podrá resolver; es una relación sujeto-sujeto; de tal modo, no se entiende la cooperación como acto de caridad, y tampoco como la imposición de agenda de un Estado a otro (objeto), y de ningún modo requiere una potencia hegemónica para que se construyan los lazos entre los Estados o para que lidere las estrategias.

Si bien se piensa desde las instituciones, se prefirió señalar el realismo cooperativo, no seguridad cooperativa, porque no se trata de la cooperación entre las Fuerzas Armadas de los Estados para servir a un Estado hegemónico, es decir, el poder pensado en términos militares, sino la capacidad de los Estados para hacer frente a sus amenazas (crimen transnacional, pandemias, cambio climático), a través de la confianza, de medidas conjuntas - no superpuestas-, que requieren que cada Estado coopere a través de sus instituciones para hacer frente común a sus amenazas corrientes, más motivados por autointerés que por un bien general.

En este caso, el problema no son Estados canallas o la amenaza de potencias extranjeras a la soberanía de los Estados, sino la incapacidad de ciertos Estados para lograr el monopolio de la fuerza y controlar en sus fronteras el crimen transnacional, que son actores no estatales que amenazan a los Estados. Esto indica que los problemas de la seguridad nacional han sido superados, por lo menos, en el contexto latinoamericano, y que nos encontramos de lleno con los problemas de la seguridad ciudadana, que por su carácter internacional

5 Según Rojas (2000), entre 1991 y 1998, el 9,6 \% de las cumbres iberoamericanas versaron sobre temas de seguridad internacional, hemisférica y regional; el 23,3 \% de las cumbres del Grupo de Río y el 12,5\% de las cumbres de las Américas. No se comparte, de Rojas (2000), el poner bajo una misma categoría la seguridad nacional y la ciudadana. Sin embargo, estos datos de la década de los 90 indican el protagonismo que tomaron los temas de seguridad en las cumbres del continente. 
compromete a los Estados en otro tipo de relaciones. ¿Qué Estado desea que otro sucumba ante la delincuencia organizada? ¿Qué Estado desea que queden en la impunidad las actuaciones extraterritoriales del crimen transnacional? ¿Cómo puede abstenerse de cooperar un Estado, si tiene la información de la comisión de posibles hechos punibles? ¿Cuál Estado no quisiera cooperar, si tiene las capacidades técnicas, de competencias y económicas que pueden contribuir a resolver un problema de afectación común? La respuesta a estas preguntas nos acerca al concepto de realismo cooperativo.

Desde luego, existen críticas a esta visión sujeto-sujeto; autores como Tickner (2013) señalan la cooperación por proxy de los EE. UU., siendo el proxy la actuación de un Estado tercero (títere) que representa los intereses de la potencia, es decir, que la cooperación en seguridad de EE. UU. se realiza a través de suplentes, en donde Colombia sería un ejemplo. Lo que no señala la autora es que este tipo de conceptos son más de la seguridad nacional (ejércitos) que de la seguridad ciudadana (policías), y que esta última es el viraje del mundo de posguerra (APARICIO, 2010). El trabajar sobre problemas compartidos, que afectan por igual a los Estados, supone nuevos desafíos para la comprensión, por parte de la academia, de las nuevas realidades.

De tal suerte, en el mundo contemporáneo, para hacer frente a los nuevos desafíos delictivos transnacionales, los Estados han recurrido principalmente, aunque no de manera exclusiva, a las actuaciones de las policías y las asociaciones de policía transnacional. Desde luego, esta cooperación señala retos y muestra límites, como una fuerza de intervención internacional de policía (MORGENTHAU, 1986).

\section{Crimen transnaCional en LATinoamérica}

Las organizaciones delincuenciales ${ }^{6}$ se nutren de varias economías criminales de financiación (narcotráfico, minería ilegal, entre otras) y sus acciones e integrantes traspasan las fronteras y afectan a los Estados de

6 Según Aparicio (2010: 29), la delincuencia organizada "corresponde a actores no estatales, algunos con vocación transnacional; e. g., los extintos carteles de la droga de Medellín y Cali, o las actuales bandas criminales del narcotráfico en Colombia ("Los Paisas", "Los Rastrojos", "Los Machos", "Renacer", Ejército Revolucionario Popular Antiterrorista de Colombia -ERPAC- y "Los Urabeños"); los carteles de la droga del Golfo, de Tijuana; los “Zetas”, de Juárez; Pacífico Sinaloa, Pacífico Sur, familia Michoacana, los Díaz Parada, Cartel de Sayaxché, Federación del Narco y Nueva Federación del Narco, en México; la Mara Salva Trucha (MS) y “La 18”, en países de Centroamérica y del Caribe...". 
varias maneras (producción, tránsito, destino), en lógicas de maximización de utilidades y menores controles de las autoridades, lo que en algunas oportunidades genera el "efecto globo", que para el caso colombiano se representa en la diáspora de narcotraficantes a otros países, que intentan evadir la justicia. En todo caso, este tipo de delitos ${ }^{7}$ viajan más rápido entre países vecinos (ARDILA, 2013).

Si bien en este artículo no se indican las condiciones por las cuales surge y se reproduce la delincuencia organizada en el continente, se puede señalar que es consecuencia de la ausencia de un monopolio de la fuerza en ciertos países de América.

Para comprender los efectos del crimen transnacional en Latinoamérica se han categorizado 16 fenómenos, correspondientes al narcotráfico, tráfico de medicamentos falsos, trata de personas, tráfico de migrantes, cibercriminalidad, delitos contra el medioambiente, tráfico de armas de fuego, municiones y explosivos, minería ilegal, hurto de celulares, falsificación de moneda, contrabando, violación de los derechos autor, marcas y patentes, hurto de automotores, hurto del patrimonio cultural, corrupción, lavado de activos, que son cometidos por las organizaciones delincuenciales.

Este no es ejercicio en el que se agote la descripción de cada fenómeno, y pueden existir otros de carácter internacional, que no se trataron, e. g., el terrorismo, o que se enmarquen dentro de otros, e. g., la pornografía infantil, que está entre fenómenos como la trata de personas y la cibercriminalidad. En tal sentido, esta es una descripción de los principales fenómenos delictivos que para su ejecución requieren pasar por varios países para su materialización, y en donde participa delincuencia organizada. En términos de Saín (2010), es una criminalidad compleja y organizada, que requiere para contrarrestarla (eliminarla, reducirla, contenerla, etc.) acciones complejas de las autoridades de los Estados.

7 Si bien no existe un código penal universal, la idea de delito, según Saín (2010), hace referencia a acciones sociales no deseadas y prohibidas, que son consideradas generadoras de algún tipo de daño o lesión sobre personas, grupos, organizaciones o colectividades. En este caso, por delito transnacional se hace referencia a conductas desviadas que tienen repercusión en varios Estados, y que cada Estado sanciona dependiendo de su legislación penal. 


\section{I. NARCotráfico}

Es el principal problema delictivo de Latinoamérica y el fenómeno transnacional que más presenta estudios y bibliografía. Para Latinoamérica, el problema contemporáneo fue que pasó de ser países productores y de tránsito, a países consumidores de estupefacientes (GONZÁLEZ, 2011), lo que transforma el panorama de criminalidad en la región.

Es alta la rentabilidad que genera la venta de estupefacientes en menores cantidades (marihuana, basuco, cocaína, heroína y pastillas de síntesis) en las urbes latinoamericanas (CORTÉS \& PARRA, 2011), además de menores riesgos comparados para poder llegar a mercados como Norteamérica, Europa y Asia; esto no significa que cesaron dichos mercados, sino que los mercados internos son tan competitivos como los de las regiones de ejemplo.

La venta de estupefacientes en las calles contribuye a la financiación de distintas organizaciones delincuenciales (carteles del narcotráfico, maras, pandillas, combos, entre otros), que a su vez alimenta otras violencias, como el homicidio y las lesiones personales, por "cobro de cuentas" o por establecer monopolios sobre la venta de estupefacientes; además, estimula otros problemas urbanos, como el hurto por parte de los consumidores o las percepciones negativas de seguridad por el consumo de estupefacientes en sitios públicos. La venta de estupefacientes en las calles es sin duda el principal problema de seguridad interméstico que se presenta en Latinoamérica.

De igual forma, han mutado las estructuras de la delincuencia organizada del narcotráfico desde la década de los 70. En Colombia se pasó de los grandes carteles a pequeños, con alta división del trabajo; de igual forma, se presenta una simbiosis entre organizaciones delincuenciales (guerrillas, bandas criminales, delincuencia organizada), que participan en diferentes fases del proceso. En México, e. g., los carteles del narcotráfico han irrumpido en todas las esferas sociales y políticas, lo cual ha sumido a este país en la más grave crisis de su historia.

Frente al efecto globo en la producción de sustancias como la cocaína, se presenta un constante cambio de las hectáreas afectadas con cultivos de hoja de coca entre Colombia, Perú y Bolivia. De igual forma, los narcotraficantes se desplazan por todo el continente, en busca de mejores 
nichos de mercado y menos control de las autoridades. Asimismo, se presenta un desvío del tránsito con rutas de estupefacientes a través de los países del Cono Sur (Chile, Bolivia, Paraguay, Argentina y Brasil), que surten a estos mercados o continúan su trayecto hacia África Occidental, con destino final Europa (España). Las rutas y modalidades de envió (correos humanos, encomiendas, barcos, lanchas, aviones, submarinos, etc.) cambian de acuerdo con los controles y el ingenio de los narcotraficantes. Lo cierto es que el mercado norteamericano es el preferido para enviar cocaína a través de rutas por México, el Caribe o el Pacífico.

Para dar una idea de la magnitud del problema del tráfico ilícito de drogas en el periodo 2003-2012 en Colombia, la Policía Nacional capturó a 768.484 personas por el delito de tráfico de estupefacientes (esto representa, año a año, el $32 \%$ del total de capturas en el país), entre ellas 1.832 extranjeros, de los cuales 593 son de nacionalidad venezolana, 292 españoles, 93 peruanos, 89 ecuatorianos y 765 de otras nacionalidades. También en el lapso 20032012 la Policía Nacional incautó 1.737 toneladas de marihuana, 734 toneladas de cocaína, 266,5 toneladas de base de coca, 20,5 toneladas de basuco, 5,5 toneladas de heroína y 2,6 millones de pastillas de drogas sintéticas.

\subsection{TRÁFico de MEdiCAMENTOS FALSOS}

Este delito repercute seriamente en la población, en los sistemas de salud de los países, y genera un impacto negativo para las empresas farmacéuticas. Según Bate (2008), tomando como fuente a la Organización Mundial de la Salud (OMS), se calcula que más del $30 \%$ de los medicamentos que se venden en Latinoamérica, África y Asia son falsos.

Existen varias modalidades, y la más frecuente es la falsificación de productos médicos; e. g., en laboratorios clandestinos, con tabletas hechas de harina de trigo, se falsifica acetaminofén?". Para la fabricación de estos productos médicos falsificados no se necesita de grandes infraestructuras o instalaciones; en la mayoría de veces son manufacturados en viviendas familiares, que se adaptan como pequeñas fábricas domésticas, con el

8 En el mundo globalizado, las calles son de doble vía, y fenómenos como el tráfico de pastillas de síntesis tienen su punto de elaboración en países europeos y de Norteamérica.

9 Son varios los elementos utilizados para el procesamiento de medicamentos falsos, como el dióxido de titanio (colorante), ácido bórico en polvo, fécula de maíz, alcohol etílico industrial, glicerina, óxido de hierro, fosfato bicálcico, diclofenaco, sibutramina, entre otros. 
propósito de no alertar a las autoridades. En todos los países de Latinoamérica se falsifican medicamentos ${ }^{10}$; sin embargo, según Ojanguren (2011), en el mundo son China e India los que concentran el $64 \%$ de la fabricación ilegal y desvío de medicamentos.

Otra modalidad delictiva es la alteración de los sellos de seguridad o de los registros sanitarios (vencidos), o la adulteración de los medicamentos (rendirlos cambiando su composición química), que son igualmente un problema para la salud. Sin agotar este tema, otro problema es el contrabando de productos médicos, en algunos casos productos auténticos o hurtados, que son desviados sin las autorizaciones legales o fitosanitarias correspondientes.

Para ilustrar el problema, en Colombia, en el periodo 2003-2012, fueron incautadas por la Policía Nacional 16,3 millones de cajas y unidades de medicamentos falsificados o que no cumplían las normas sanitarias.

\subsection{TRATA DE PERSONAS}

A pesar de ser un delito priorizado por varias ONG del mundo, y de tener una abundante legislación mundial para combatirlo, se sigue presentando con regularidad; la modalidad con mayor ocurrencia es la explotación sexual de mujeres, y también el trabajo forzado, la servidumbre doméstica y la mendicidad infantil. Cerca de dos tercios de las víctimas corresponden a mujeres (UNODC, 2014).

La trata de personas con fines de explotación sexual está ligada al proxenetismo, en el cual básicamente las víctimas, producto de los servicios sexuales prestados, deben dar una cuota económica a las organizaciones delincuenciales que se encargaron en un comienzo de los costos de los pasajes, pasaportes, visas, entre otros, para ubicar a la víctima en otro país; en su mayoría las víctimas son engañadas, ya que desconocen los altos montos que cobran estas organizaciones por su traslado. Desde Colombia, los principales países de destino de las víctimas son Panamá, España, Japón, Ecuador y China (Hong Kong). Pero también Colombia es destino; e. g., en zonas de frontera entre Venezuela y Brasil existe explotación sexual de mujeres de estas nacionalidades.

10 En Latinoamérica, la ausencia de una legislación disuasiva también constituye un incentivo, pues quienes se dedican a estas actividades ilícitas no temen ser detenidos. A esto se añade la venta de productos por internet, que facilita la distribución y garantiza el anonimato de los victimarios. 
En el lapso 2003-2012 en Colombia se ha capturado a 559 sujetos por trata de personas, de los cuales seis eran extranjeros (Ecuador, México, Venezuela y EE. UU.).

\subsection{Tráfico de MIGRANTES}

Está ligado a las olas migratorias del mundo. Es un fenómeno en el que las organizaciones delincuenciales se especializan en ingresar ilegalmente (por tierra, mar o aire) a otros países a los migrantes, que por lo general corresponde a un acuerdo de voluntades. Para ello, la delincuencia organizada emplea varias modalidades, como la creación de falsos perfiles para obtener visas, el ingreso legal mediante la realización de falsos eventos (modelajes, congresos, seminarios, etc.) o el ingreso por terceros países con guías (coyotes).

En el continente esta situación se presenta históricamente en la frontera entre los EE. UU. y México. Lo particular en los últimos años son rutas de tránsito hacia los EE. UU. por Latinoamérica, de ciudadanos africanos, indios, del sudeste asiático y chinos.

Colombia es considerado como un país de origen y de tránsito de migrantes (UNODC, 2013). En el lapso 2003-2012 la Policía Nacional capturó a 156 personas por tráfico de migrantes; de ellas, 24 eran extranjeros (quince de Ecuador, cuatro de Perú, dos de Nepal, uno de Brasil, uno de Nigeria y uno de Panamá).

\subsection{Cibercriminalidad}

A medida que se masifica el uso de las tecnologías informáticas, como internet, también aumentan las conductas delictivas, que utilizan la red como medio facilitador del hecho punible, entre otros el hurto, la estafa, la pornografía infantil y el acceso ilegal a información, con el propósito de buscar un lucro económico (cuentas bancarias), satisfacción sexual o perjudicar empresas con el propósito de crear caos.

Esto indica un cambio del perfil de la delincuencia; de hecho, no se necesita de grandes organizaciones, ya que se trata de expertos en informática con diversas motivaciones para cometer sus ilícitos, que algunas veces actúan 
solos; también se presenta anonimato, ya que la víctima (personas naturales o jurídicas) y el victimario pierden el contacto físico. De hecho, los servidores y los lugares donde se encuentran las personas pueden corresponder a distintos países, de modo que no se emplean armas de fuego, y en tal sentido disminuyen los riesgos y aumentan las ganancias. Dado su carácter reciente, existen vacíos legales para combatir el hecho ilícito, y para agravar la situación, los criminales presentan alta adaptación.

En Colombia desde el año 2009, cuando se reformó el Código Penal para contemplar los delitos informáticos, se han presentado un total de 5.820 denuncias; se ha observado un incremento del $475 \%$ de estas en cuatro años. El $57 \%$ de estos casos fue por el delito de "burto por medios informáticos y semejantes", y el $16 \%$ por "acceso abusivo a un sistema informático".

\subsection{Delitos Contra EL MEDIOAMbiente}

Se calcula que al año se trafican más de 635 millones de animales y plantas en el mundo (ALVARADO, 2012, p. 300). El tráfico y extracción ilegal de especies -fauna y flora- tiene una demanda tanto interna como externa (principalmente mercados de Norteamérica, Europa y Asia).

Los usos de las especies de fauna son por lo general para ornamentación y mascotas, en algunos casos como medicinas y en otros como alimentos. Para la flora, se emplea especialmente para la extracción de madera (URREGO, PÉREZ, POLANCO \& PÉREZ, 2012), y también tiene usos ornamentales y medicinales.

Las especies más traficadas corresponden a los peces ornamentales, caracoles, aves, mamíferos, reptiles, insectos y variedades de flora silvestre. Como Latinoamérica es potencia en biodiversidad, el daño ambiental y ecológico que generan estas prácticas es dramático.

En el lapso 2003-2012, en Colombia, se han capturado 18.016 personas, por delitos contra el medioambiente, de las cuales 77 eran extranjeros (Perú 31, Ecuador 18, Venezuela nueve, Costa Rica cinco, Brasil cuatro y otros diez). En el mismo periodo, la Policía Nacional ha recuperado 5.108 .881 unidades de fauna (peces $61 \%$, caracoles $6 \%$, babilla $1 \%$, tortugas $1 \%$ y otros $31 \%$ ). Y se han incautado 3.266 .993 unidades de flora (palma de cera $65 \%$, cañabrava $4 \%$, pino colombiano $4 \%$ y otros $27 \%$ ). 


\subsection{Tráfico de ARMAS de FUEGO, MUNICIONES Y EXPLOSIVOS}

Es un problema mayúsculo en Latinoamérica (SMALL ARMS SURVEY, 2011), ya que las armas de fuego y el homicidio tienen una relación directa (CLERKE \& ECK, s/f), comprobada en Colombia con una relación año a año superior al $70 \%$ sobre el total de muertes violentas (CASAS, 2006). Además, las armas de fuego son fuente de poder de la delincuencia organizada y la subversión. Con la tenencia de armas de fuego la delincuencia organizada extorsiona a la población en sectores deprimidos de las ciudades, bajo el presupuesto de "brindar seguridad".

El tráfico de armas de fuego, municiones y explosivos se volvió mayúsculo en el continente luego de la Revolución Cubana, en particular para surtir a los grupos guerrilleros y posteriormente de derecha. Algunos remanentes de las armas de fuego que se emplearon en los conflictos de Centroamérica ingresaron a países como Colombia. Pero es necesario indicar que el problema no solo es en países con conflicto interno o posconflicto, ya que la tenencia de armas de fuego es también amplia en países sin conflicto o que no atravesaron por él (GENEVA DECLARATION, 2008), como es el caso de Jamaica o Haití.

El tráfico de armas ligeras y municiones es el más extendido, frente a situaciones como el tráfico de explosivos o armas de fuego pesadas. En su mayor parte, las casas de fabricación de armas livianas y municiones son de países de Europa, Asia y Norteamérica (VRANCKX, 2009). Sin embargo, en los contextos locales también se fabrican armas de fuego, en algunos casos artesanales (hechizas), que surten a la delincuencia y otras organizaciones menores, como industrias nacionales (para Colombia el caso Indumil), que por situaciones de falta de control sobre municiones y armas paran en la delincuencia.

En tiempos recientes, en Latinoamérica, se ha presentado el fenómeno del intercambio de armas de fuego por drogas ilícitas, en particular entre organizaciones delincuenciales de México y Colombia.

Para dar una idea del fenómeno, entre el 2003 y el 2012 se han capturado 181.693 personas, por tráfico, porte o tenencia de armas de fuego y municiones, de las cuales 268 eran extranjeras (Venezuela 178, Ecuador 32, Perú 12, EE. UU. nueve y otros 37). 


\subsection{Minería ILEGAL}

La "maldición de los recursos" (COLLIER, 2001) es otro de los problemas intermésticos que afectan a Latinoamérica, en donde existen organizaciones delincuenciales que se han dedicado a las extracciones ilícitas de oro, plata, platino, coltán, esmeraldas, arena, gravilla, carbón, sal, uranio, etc., insumos que son esenciales para ciertos tipos de industria, como la joyería, la construcción, la de circuitos electrónicos, etc.

En Colombia es fuente de financiación de la delincuencia organizada y la subversión (que también se nutren de otras economías criminales, como el narcotráfico, la extorsión y el secuestro).

Es un delito que para su ejecución se vale de otros, como la apropiación y usurpación de tierras, desplazamiento forzado o la corrupción administrativa para la consecución de permisos y licencias de explotación. También produce otros delitos, como la destrucción de ecosistemas y hábitats de miles de especies de fauna y flora silvestre, además de la contaminación (principalmente con mercurio) y agotamiento de las aguas. En ciertos países los límites de labores de minería legal e ilegal se hacen difusos, y dentro de la minería ilegal existen procesos de extracción industriales (el empleo de retroexcavadoras, dragas, etc.) y artesanales (“barequeros”).

En Colombia, en el periodo 2003-2012, se han capturado 5.769 personas por minería ilegal, de las cuales 27 son extranjeras.

\subsection{HuRTO DE TElÉFONOS MÓVILES}

Es el delito que genera mayor impacto en la ciudadanía en Colombia, ya que dentro del delito del hurto, es el objeto que más se roban (CÁMARA DE COMERCIO DE BOGOTÁ, 2014, p. 40).

Aunque parece un fenómeno local de los países, en la última década se convirtió en un problema internacional (APARICIO, 2011), ya que los teléfonos móviles que no se pueden activar (reutilizar abriendo bandas) en un país son enviados a otros por redes internacionales de delincuencia organizada, como, e. g., Argentina, México, Perú, Ecuador, Bolivia, Venezuela, Chile, Costa Rica, Honduras y Colombia. Para enviarlos son 
transportados por correo certificado y transporte humano, y en las fronteras se realizan intercambios de tarjetas de celular.

\section{IO. FALSIFICACIÓN DE MONEDA}

La fabricación clandestina e ilegal de pesos, dólares, euros, bolívares y otras monedas locales afecta gravemente la economía de los Estados. Es un delito que lleva más de medio siglo presentándose en Latinoamérica.

Este delito se ha volcado principalmente a la falsificación de dólares, en donde la delincuencia organizada, que se caracteriza por tener clanes familiares, busca rutas de economías dolarizadas o con importante afluencia de turistas, como EE. UU., Ecuador, Panamá e islas del Caribe.

Tan solo en los últimos nueve años, en Colombia, la Policía Nacional ha logrado la incautación de 1.362 millones de bolívares, 267.353 millones de dólares y 19.139 millones de euros, todos falsos.

\section{4. i i. Contrabando}

Es el delito transnacional más antiguo, ya que se liga al monopolio tributario, que es uno de los ejes esenciales del Estado-nación (ELIAS, 2009). Para Latinoamérica, está presente desde la Colonia. Se caracteriza por la evasión de impuestos o aranceles, lo que perjudica las finanzas públicas y genera corrupción administrativa ${ }^{11}$.

En la actualidad, los principales bienes de contrabando abierto son los licores, cigarrillos, alimentos básicos de la canasta familiar, hidrocarburos, calzado, ropa, perfumería y electrodomésticos.

Sin embargo, son varias las formas en que se presenta el contrabando; una de ellas es el técnico, que consiste en el ingreso de mercancías con presentación y declaración, pero que por una serie de maniobras fraudulentas se altera la información que se le presenta a la autoridad aduanera, con el propósito de subfacturar, sobrefacturar, evadir el cumplimiento de requisitos legales, cambiar la posición arancelaria u obtener otros beneficios aduaneros o tributarios.

11 En Colombia, las rutas y modus operandi de los contrabandistas en la costa norte fueron las asumidas por las organizaciones del narcotráfico. Es de indicar que una forma de blanquear los dineros del narcotráfico es a través de la compra de mercancía, que luego ingresa de contrabando. 


\section{I 2. VIOLACIÓN DE LOS DERECHOS DE AUTOR, MARCAS Y PATENTES}

La elaboración de productos falsificados tiene un impacto económico del 7 al $9 \%$ del comercio mundial, es decir, de US\$ 450 a 500 mil millones al año (ILEA, 2012). En este fenómeno delictivo confluyen la falsificación de mercancías, la falsedad marcaria, la usurpación de marcas, el plagio y la violación de los derechos de propiedad industrial. Se calcula que el $62 \%$ de las mercancías falsificadas provienen de la China (ILEA, 2012).

Asimismo, las organizaciones delincuenciales recurren a varios fenómenos delictivos al tiempo, como la falsificación, el contrabando, la estafa, la corrupción de alimentos y medicamentos y los delitos tributarios.

Los productos o mercancías más falsificados corresponden a ropa (Lacoste, Umbro, Tommy Hilfiger, Abercrombie \& Fitch, Hollister, etc.), calzado (Nike, Reebok, Adidas, Puma, etc.), cigarrillos (Marlboro, Lucky Strike, Belmont, etc.), perfumes (Lacoste, Boss, Calvin Klein, etc.), medicamentos, electrodomésticos (LG, Sony, etc.), elementos electrónicos (Blackberry) y baterías. Es de gran impacto para Latinoamérica la reproducción ilegal de libros y de software, música, películas y juegos de video en formatos de CD, DVD y memorias USB.

Sin embargo, otro tipo de falsificación de productos afecta la salud pública, como la corrupción de alimentos, e. g., el reenvasar aceite de cocina usado, el llenar envases de gaseosas más costosas con otras de menor precio; también la corrupción de productos, e. g., el reenvasar aceite para vehículos, o reenvasar champú o blanqueador. Estos ejemplos ilustran el nivel de imaginación para la comisión de este ilícito.

\section{I 3. HURTO DE AUTOMOTORES}

En el caso colombiano, en menor proporción, los vehículos hurtados son transportados a través de las fronteras terrestres hacia Venezuela, Ecuador, Perú y Bolivia. En algunos casos los vehículos son adulterados en sus placas y sistemas de seguridad, y en otros son comercializados como autopartes.

En el periodo 2003-2012 fueron capturadas en Colombia 31.032 personas por hurto de vehículos, de las cuales 50 eran venezolanas, diez 
ecuatorianas, cuatro peruanas y nueve de otras nacionalidades. Y fueron recuperados en Colombia 202.697 vehículos, de los cuales 2.736 eran de matrícula venezolana, 122 de Ecuador y tres de Brasil.

\section{I 4. Hurto del patrimonio CUltural}

Desde la época de la Conquista se presentan este tipo de hechos. Por lo regular comienzan con la "guaquería", en especial piezas precolombinas; sin embargo, existen organizaciones delincuencias que se especializan en el hurto de obras de arte, pinturas, objetos religiosos, que finalmente son enviados a coleccionistas privados en todo el mundo.

Entre el 2003 y el 2012 se han capturado 158 personas por hurto al patrimonio cultural de la nación, de las cuales dos son extranjeras (Ecuador y Venezuela).

\section{I 5. CORRUPCIÓN}

Para muchos, es el principal factor de la precaria situación social y económica de Latinoamérica, pues es una de las regiones del mundo con menor nivel de transparencia. Está ligada principalmente a la contratación administrativa y los intereses de las grandes compañías transnacionales, pero también a pequeños intereses mezquinos, que para lograr ventajas o mayores márgenes de ganancia recurren a la corrupción de funcionarios públicos.

Los delitos de "cuello blanco" y los administrativos son una serie de títulos penales, como la concusión, el peculado y el cohecho. Un tipo de corrupción corresponde a organizaciones con alto nivel educativo o en posiciones de privilegio en la administración pública; e. g., en Colombia es reciente el caso de la devolución de impuestos por exportaciones ficticias de la DIAN y otros, como Ferrovías, Caprecom, Foncolpuertos, Termorio, Chivor, Dragacol, el carrusel de la contratación en Bogotá, etc.

\section{I 6. LAVADO DE ACTIVOS}

En este confluyen los demás delitos transnacionales, ya que la delincuencia organizada requiere retornar los dineros de carácter ilícito; son 
varias las modalidades del blanqueo de capitales ${ }^{12}$, para lo cual la delincuencia organizada emplea expertos economistas y contadores. Según el Fondo Monetario Internacional (FMI), el lavado de activos en Latinoamérica representa entre el 2,5 \% y el 6,3 \% del PIB regional anual (PNUD Guatemala, 2009).

En el lapso 2003-2012, en Colombia, fueron capturadas 1.389 personas por lavado de activos, de las cuales 15 eran extranjeras (México cuatro, Venezuela cuatro y siete de otros países), y la Policía Nacional presentó ante las autoridades judiciales 46.607 bienes y ocupó 19.094 .

\section{ACCIONES de los Estados FRENTE A LOS FENómenos TRANSNACIONALES A TRAVÉS DE LAS POLICÍAS}

A problemas comunes, las soluciones, de igual manera, deben ser comunes. En tal sentido, se plantea la hipótesis de que luego de la Guerra Fría la cooperación entre las agencias públicas de los Estados creció, para hacer frente a los fenómenos criminales comunes de carácter transnacional.

Se han señalado 16 de los problemas de mayor trascendencia en Latinoamérica que derivan de la delincuencia organizada transnacional, y que también los Estados recurren a la cooperación para hacer frente a ello, principalmente desde persecución penal, lo que compromete a varias instituciones, como fiscalías, ministerios públicos, policías, fuerzas militares, unidades de lavados de activos, instituciones de impuestos, entre otras. Pero el papel más preponderante lo han asumido las instituciones de policías.

Sin embargo, la cooperación internacional entre los Estados a través de las policías es un hecho contradictorio, ya que la policía entendida en la prevención del delito mediante la aplicación de la ley o el aparato encargado de la coacción interna del Estado (MONJARDET, 2010), y de garantizar las condiciones de convivencia, es una institución que comenzó en el siglo XIX (WILSON, FYFE, GREENE, WALSH, \& CLINTON, 1997;

12 E. g., las exportaciones ficticias de servicios; exportaciones ficticias de bienes; arbitraje cambiario internacional mediante el transporte de dinero ilícito; transferencia fraccionada de dinero ilícito a través de giros internacionales; "peso broker"; utilización de empresas legalmente establecidas para apoyar actividades de organizaciones delincuenciales; utilización de fondos ilícitos para disminuir deuda o capitalizar empresas legítimas; compra de premios por parte de organizaciones delincuenciales; declaración de un premio ficticio obtenido en el exterior; lavado en operaciones notariales. Se han detectado otras modalidades, como la compra de servicios de internet y telefonía móvil, la compra de tarjetas prepago o la supuesta venta de productos de consultoría. 
NEOCLEOUS, 2010), y se entendió como el mantenimiento del orden interno a través de la fuerza (ley) o la amenaza de ella, desde las funciones de la policía administrativa, la policía judicial y la inteligencia (APARICIO \& POVEDA, 2013).

Ello muy pronto comenzó a variar, ya que desde principios del siglo XX se identificó que los delincuentes y los delitos traspasaban las fronteras nacionales. De esta manera, los Estados iniciaron procesos de entendimiento (tratados, convenios, acuerdos, etc.), con el propósito de contrarrestar este tipo de situaciones; con el tiempo se empezaron a ejecutar tratados de extradición para aquellos delincuentes que cometían un delito en un Estado y buscaban refugio en otro.

Con los procesos de descolonización y creación de nuevos Estados, las iniciativas de cooperación entre policías y este tipo de organizaciones se extendieron a todo el mundo. De esta forma, las policías y la cooperación entre ellas son un fenómeno universal.

Como indica Casey (2010, p. 394), "las agencias del orden público fortalecen las relaciones entre sus contrapartes de otros países, emprenden operaciones conjuntas, intercambian información y comparten instalaciones mediante instituciones específicas de policía, tales como la Interpol...”.

De esta manera, las policías en el mundo contemporáneo ya no tienen un papel solo interno, sino que su desempeño trasciende fronteras, $y$ son parte activa de la diplomacia de los Estados (misiones policiales).

Así, en el mundo contemporáneo, frente a las labores de policía, en un realismo cooperativo se presentan tres nuevos fenómenos: i) la cooperación bilateral entre Estados y sus policías; ii) las misiones internacionales de paz promovidas por la ONU, con presencia policial, y iii) organismos internacionales de cooperación transnacional en asuntos de policía.

\section{I. ACUERDOS BILATERALES QUE COMPROMETEN A LAS POLICÍAS}

Los Estados en Latinoamérica han suscrito diversos tratados por más de un siglo, para hacer frente a fenómenos delincuenciales. Es común que los Estados tengan tratados de extradición y cooperación frente al crimen transnacional. 
Los acuerdos bilaterales de cooperación con temas de policía son comunes en Colombia desde la década de los 80; al inicio como país receptor de ayuda, principalmente de los EE. UU. y de países europeos, como el Reino Unido, para luego ser país "donante" de cooperación (LONDONO, 2010), que cumple múltiples asesorías en Centro y Suramérica (Panamá, Ecuador, República Dominicana, Haití, México, Paraguay, Honduras, Guatemala, etc.).

Para este tipo de acuerdos los Estados han promovido diversas herramientas, como las extradiciones (activas y pasivas), acuerdos de capacitación y formación policial, entrega de información, operaciones conjuntas, suministro de know how en procedimientos y métodos policiales. Este nuevo énfasis se demuestra en que a la par de las tradicionales y protocolarias agregadurías militares también se instalan agregadurías policiales, y es este un nuevo cambio en las misiones diplomáticas de los Estados ${ }^{13}$.

También existen situaciones que implican destinación directa de funcionarios, y que señalan un mayor compromiso entre Estados; e. g., en eventos internacionales, como el Mundial de Fútbol de la FIFA - Brasil 2014, existió apoyo de organismos de policía para labores particulares, como guías caninos y explosivistas (POLICÍA NACIONAL, 2014). O como los acuerdos bilaterales entre Australia e Islas Salomón, para que la Policía Federal Australiana se encargue de las labores preventivas de policía en la isla $\left(\right.$ CASEY, 2010) ${ }^{14}$.

Entre los tratados, acuerdos en cumbres, memorandos de entendimiento y convenios bilaterales entre los Estados para combatir la delincuencia transnacional, Colombia es ejemplo mundial de cooperación, ya que la Policía Nacional, al 2014, presenta vigentes 131 instrumentos de cooperación, de los cuales 126 son acuerdos de cooperación bilateral ${ }^{15}$. Todos estos pasan desde actividades para la prevención de delitos transnacionales, asistencia técnica antinarcóticos, intercambio de información, experiencias para combatir el crimen, extradiciones, cooperación en investigación

13 Algunas críticas a las misiones diplomáticas es su excesivo énfasis en la promoción comercial. De igual forma, el limitar las relaciones internacionales solo a aspectos económicos, restando énfasis a otros aspectos, como los políticos y de cooperación en cuestiones de seguridad.

14 Esta situación se dio por el rol protagónico de Australia en Oceanía y la necesidad de poner fin al conflicto civil en la isla. Esta intervención se presentó entre el 2003 y el 2013.

15 Existen convenios internacionales en la lucha contra el crimen organizado con 39 países y enlaces con las principales agencias policiales; e. g.: DEA, ICE, Europol, etc. Apoyo a operaciones en investigación criminal en 36 países, a operaciones de inteligencia en 58 naciones y a operaciones antisecuestro y antiextorsión en nueve países. 
criminal, capacitación de policías ${ }^{16}$, ayuda en recursos tecnológicos, hasta acciones operativas conjuntas.

Como forma de mostrar la cooperación frente a la delincuencia transnacional, en Colombia se han capturado, del 2003 al 2012, un total de 5.085 extranjeros; de ellos, el $66 \%$ son originarios de los países que tienen límites terrestres con Colombia (Venezuela, Ecuador, Perú, Brasil y Panamá), y la mayoría de las capturas corresponden a los delitos de tráfico, fabricación o porte de estupefacientes, y por hurto. También la Policía Nacional, en los últimos nueve años, ha capturado a 1.070 personas que son requeridas por autoridades extranjeras por conductas cometidas en esos países, y ha realizado los procesos de extradición de 1.527 colombianos.

\subsection{MisioneS DE PAZ INTERNACIONALES CON POLICÍAS}

En el ámbito internacional se empiezan a privilegiar los contingentes para "el mantenimiento de la paz" con presencia policial (MARTÍNEZ, 2001; APARICIO, 2010), con el propósito de garantizar condiciones de tranquilidad y estabilidad interna en aquellos países que requieren "Operaciones para el Mantenimiento de la Paz" - OMP, o como señaló Boutros-Ghali (1992, p. 2), "la consolidación de la paz después de los conflictos", con despliegue en el terreno de la ONU con "la participación de personal militar o policial de las Naciones Unidas y... personal civil” (p. 6).

Este tipo de operaciones, sin ser un fenómeno nuevo ${ }^{17}$, presenta un auge en los últimos años (MARTíNEZ, 2001, p. 317). De tal forma, del total del contingente de la fuerza de las misiones de paz de la ONU (104.320 personas), para el año 2013 un $12 \%$ eran policías (ONU, 2014).

Uno de los retos de la paz entre las naciones consiste en la estabilidad interna entre los Estados; esta situación tuvo asidero mundial luego de la caída del Muro de Berlín, presentándose una serie de intervenciones permitidas por los gobiernos de los Estados que se encontraban en crisis (guerra civil, deficiencia de instituciones, colapso de las instituciones policiales, catástrofes

16 Colombia ha capacitado en policía, por más de seis décadas, en sus escuelas de formación policial, a ciudadanos de Panamá, Honduras, Bolivia, Venezuela, Ecuador y Haití. Además, ha dictado diversos cursos y diplomados, que comprometen a distintas policías del mundo.

17 Según Boutros-Ghali (1992, p. 15), entre 1945 y 1992 se presentaron 26 operaciones de mantenimiento de la paz. 
naturales, etc.) y apoyados por resoluciones consensuadas de la ONU; entre los ejemplos se encuentran las misiones de paz (2. ${ }^{a}$ generación de OMP, MARTÍNEZ, 2001), con participación de policías en el Congo desde 1989 (MARTÍNEZ, 2001), la antigua Yugoslavia, Camboya, Angola, Guatemala, El Salvador, Guinea Bissau, Sierra Leona, Haití (LONDOÑO, 2010), Timor del Este y Papúa Nueva Guinea (CASEY, 2010).

Para estas OMP los países amigos suministran contingentes de policía, que en comisión en la ONU cumplen diversas tareas, como apoyo administrativo, desarme, garantía de neutralidad ante la población, preparación y adiestramiento (capacitación) de personal, asistencia en labores preventivas, restablecimiento del orden, entre otras.

\subsection{ORgANISMOS INTERNACIONALES DE POLICÍA}

La presencia de policía en las OMP no significa una policía mundial. Lo que se ha presentado desde el siglo XX es la necesidad de crear organismos supranacionales de policía, que permitan la cooperación entre los Estados para combatir problemas comunes del crimen transnacional.

Para este propósito los Estados crearon organismos internacionales, como Interpol, que es una organización de la $\mathrm{ONU}^{18}$, pero también regionales, como Europol, para Europa, siendo este un organismo de la Unión Europea, y más recientemente Ameripol, para América y perteneciente a la OEA ${ }^{19}$.

Este último tipo de organismos internacionales se valen para su cooperación de la comunicación directa entre las policías de los países que son altas partes contratantes. Estos medios de cooperación permiten

18 Esta situación hizo pensar a los Estados que además era necesario crear canales que facilitaran la captura de prófugos internacionales; fue así que en 1914 se realizó el Primer Congreso Internacional de Policía Criminal, en Mónaco, y en 1923 se creó la Comisión Internacional de Policía Criminal (CIPC), con sede en Viena (Interpol, 2014), y en 1956 pasa a llamarse Organización Internacional de Policía Criminal (Interpol). Estas primeras iniciativas nacen en el continente europeo, y se fortalecieron en el mismo; e. g., en los procesos de integración de la Unión Europea se creó, en 1999, la Europol, que tiene por objetivo el "intercambio y análisis de información sobre actividades delictivas" (2014), por las policías de los países que integran la UE.

19 De hecho, organismos hemisféricos, como la OEA o Mercosur, abordan entre sus documentos los asuntos del crimen transnacional. Como indica Aparicio (2010): "acuerdos regionales como los suscitados por la OEA y su Comisión de Seguridad Hemisférica, para prevenir, disuadir y controlar el fenómeno criminal en Latinoamérica, o el Acuerdo Marco de Cooperación en Materia de Seguridad Regional entre los Estados parte del Mercosur". 
compartir información de valiosa utilidad, como órdenes internacionales de detección de delincuentes, búsqueda de desaparecidos, solicitud de vehículos y pasaportes hurtados, entre otros. Pero también estos canales permiten el compartir información operativa, en algunas oportunidades operaciones conjuntas entre las policías y más recientemente la capacitación de funcionarios policiales.

La cooperación para combatir el delito transnacional tiene varias décadas; basta solo recordar que en 1923 se creó la Comisión Internacional de Policía Criminal (CIPC), que es el antecedente de Interpol, y desde 1946 se dispone de herramientas para la persecución de prófugos, como las notificaciones rojas, y agencias que estudian el fenómeno transnacional y promueven políticas, como la Oficina de las Naciones Unidas contra la Droga y el Delito (UNODC).

La idea de ahondar en organizaciones de cooperación frente al delito en el continente tuvo su más alto componente en el año 2007, con la creación de la comunidad de policías de América (Ameripol) (APARICIO, 2010), como propuesta similar a Europol, para contrarrestar desde las policías el crimen transnacional. Esta organización es una nueva institución de la OEA.

\section{Discusión}

La globalización o mundialización lleva consigo como reto la transnacionalización del delito, y esto tiene como oportunidad la cooperación entre los países, principalmente entre sus instituciones de policía, para hacer frente a problemas que son comunes a los Estados. El tradicional juego de espías, recelo entre países y cancillerías de protocolo, da paso a nuevas dinámicas de políticas internacionales en el siglo XXI, entre ellas el papel más protagónico de las instituciones de coacción y prevención como las policías, lo que renueva el papel de cancillerías, el Derecho internacional y la cooperación entre Estados.

Los papeles que desempeñan los cuerpos de policía frente a la colaboración de los Estados son los acuerdos de cooperación bilaterales, las misiones internacionales de paz con asistencia de policías y los organismos internacionales de policía, como la ONU -Interpol- y la OEA -Ameripol-. Estos papeles permiten ver la necesidad de creación de una fuerza policiaca internacional. 
Sin embargo, estos papeles, dejan planteado el reto de Morgenthau (1986, p. 504) de "las esperanzas de preservar la paz asociadas a una fuerza policiaca internacional derivan de la analogía con las funciones que, dentro de las sociedades domésticas, cumple la policía”. Más aún, frente a la posibilidad de una fuerza policiaca internacional, el mismo autor señala que (p. 505): "En una sociedad de Estados soberanos, una fuerza policiaca internacional es algo contradictorio". Para el mundo contemporáneo una fuerza policiaca internacional es una quimera. Sin embargo, es necesario señalar que Morgenthau pensaba en el control entre Estados (policía mundial), no los Estados colaborando en problemáticas comunes que los afectan por igual. Si bien no se ha llegado a una fuerza policiaca internacional, el mundo de posguerra muestra la creciente cooperación y organización mundial de las policías, que a todas luces es un cambio en la política internacional.

En todo caso, los estudios frente a la política internacional en el mundo de posguerra no han sido prolíferos en plantar nuevos escenarios ante la cooperación entre los Estados, menos aún frente a las labores que cumplen instituciones como las policías en el nuevo contexto mundial. Es esta una veta que debe explorar la academia. En realidad, la ciencia política o las relaciones internacionales no han ahondado en las instituciones policiales, y cómo desde ellas pueden darse soluciones o sencillamente ver las cosas desde otro punto de vista.

Las agendas de los Estados han priorizado energías en actividades de cooperación multilateral judicial, policial e información criminal, que confluyan en órbitas como la coerción, la prevención y la disuasión de los problemas intermésticos del delito transnacional, y la delincuencia organizada como nuevo actor no estatal de la globalización.

La irrupción problemática de la delincuencia organizada forzó a los Estados en Latinoamérica a acordar, mediante diferentes mecanismos, acciones de cooperación. Frente a las nuevas agendas, las labores de las cancillerías son limitadas ${ }^{20}$, y tienen más peso otras agencias del Estado, como los ministerios del Interior y Defensa o instituciones como las policías.

Los efectos del delito transnacional han significado un cambio de las prioridades de los Estados frente a la seguridad de sus ciudadanos;

20 Frente al papel de las cancillerías en las nuevas dinámicas, como apunta Riordan (2005), también las embajadas y cancillerías se han especializado en auxiliar a los conciudadanos con problemas penales. 
estos delitos se pueden caracterizar por la participación de la delincuencia organizada en su comisión. La descripción de algunos delitos con carácter transnacional en Latinoamérica ofrece una dimensión de la problemática. Aunque la descripción es necesaria, la teoría en relaciones internacionales es insuficiente. Lo cierto es que los Estados han tomado una serie de acciones con el propósito de hacer frente a este reto de la globalización, lo que se ha indicado como realismo cooperativo.

Aunque se ilustra con el caso de las policías, lo cierto es que la agenda de cooperación frente al crimen transnacional es para todas las instituciones que se encargan de hacer cumplir la ley (fiscalía, rama judicial, procuraduría, etc.). De hecho, para hacer frente a la delincuencia transnacional, las labores de las policías son solo uno de los factores que se deben tener en cuenta. Es un error pensar que los problemas internacionales del crimen transnacional solo se superaran con la acción policial, situación que no corresponde a la realidad. Que se señale el papel de las agencias policiales en el nuevo contexto internacional no indica que es determinante en última instancia.

Sin embargo, la lucha contra el crimen transnacional no deja de tener contrasentidos, como la participación de las fuerzas armadas en este tipo de tareas (SANSÓ-RUBERT, 2013) o los intentos de estas por tener más prerrogativas legales para participar en ello.

Frente a las acciones de los Estados, estos se basan en las fortalezas de sus instituciones, y por desgracia, las encargadas de implementar la ley se encuentran en diferentes desarrollos, inclusive dentro del mismo Estado. Para Latinoamérica, algunas instituciones no aportan en lo que en términos weberianos (WEBER, 2007) corresponde a lograr un monopolio de la fuerza en su territorio por un gobierno legítimo.

También, la cooperación que se requiere para enfrentar el crimen transnacional no es entre iguales, lo que indica que la cooperación no solo es desde un punto de vista operativo, sino que se liga a aspectos como la educación (capacitación), el traspaso de conocimiento y métodos, y el compartir tecnologías.

Es necesario ver los límites de las mismas policías. El desarrollo desigual de estas, la hiperdescentralización de algunas, la insuficiencia de recursos y de capacidad operativa de las agencias que hacen cumplir la ley, todo ligado 
muchas veces al déficit de capacitación y bajos perfiles, la corrupción, entre otros, son una serie de problemas que deben revisarse con detalle.

Es un problema fundamental que hasta el momento no existe una evaluación de cada uno de los acuerdos, entendimientos, actas, pactos, etc., firmados por los Estados y que comprometan los asuntos de seguridad ciudadana; tampoco los impactos de la cooperación, a partir de las agencias policiales, para la contención, mitigación o eliminación de los fenómenos y delincuencia organizada que hemos descrito en este artículo.

Otros problemas, que por espacio no se tuvieron presentes en el artículo, fueron la integración y la superposición de competencias en las instituciones de cada Estado; e. g., las funciones de policía judicial en varios cuerpos, las entidades que participan de la política exterior, las competencias de militares y policías aún borrosas en países de Latinoamérica; también las dificultades para que en y entre los Estados definan estrategias comunes frente a la delincuencia organizada y los fenómenos señalados; no se exploraron las formas en que los Estados acuerdan, y los resultados de las reuniones para cada ítem de seguridad; tampoco se ahondó en las nuevas dinámicas de reformas a las instituciones en el continente, que impactan sobre la policía y sus labores, como, e. g., la reforma en la mayoría de los países de los códigos penales y procesales penales (populismo punitivo). De igual manera, no se presentó una evaluación sobre los tratados, acuerdos, convenios, etc., para hacer frente al crimen transnacional; a ciencia cierta, todavía no existen índices para comprobar la eficacia, eficiencia o efectividad de estos en Latinoamérica.

\section{RECOMENDACIONES}

Lo señalado hasta aquí sobre los problemas intermésticos del continente, la cooperación de los Estados y la participación de las policías frente a estos problemas, más las discusiones plantedas, permiten formular algunas recomentaciones generales para los gobiernos:

a. El ahondar los programas de cooperación desde las agencias encargadas de la aplicación de la ley es la principal recomendación para los gobiernos del continente, con el propósito de hacer frente a la delincuencia organizada con carácter transnacional. Esta cooperación puede surgir de acuerdos bilaterales o multilaterales. 
b. Sin embargo, la cooperación debe ser más especializada, casi por temática o problema de seguridad. Dado que se trata de situaciones complejas, deben intervenir las instituciones homólogas, que por función están comprometidas para resolver ciertos problemas. De hecho, la cooperación a través de organismos internacionales de policía resulta de importante utilidad, ya que facilita la comunicación entre estas instituciones.

c. La cooperación se presenta en diferentes vías y niveles; en tal sentido, los Estados deben promover diversos mecanismos, como las extradiciones (activas y pasivas), capacitación y formación, suministro de información y procedimientos, operaciones conjuntas, apoyo económico y trasferencia de tecnología y bienes. Desde luego, la vía represiva no es exclusiva, la prevención y la disuasión también son temas de vital importancia en las agendas de seguridad de los Estados. Sin embargo, es necesario que las cancillerías asuman el liderazgo y centralización de estas funciones, y se adecuen a los nuevos escenarios del mundo pos-Guerra Fría.

d. De hecho, los diagnósticos de los problemas, realizados de manera oficial por los Estados, deben ser lo suficientemente amplios, conociendo sus causas y consecuencias; en este sentido, los acuerdos deben basarse en información empírica.

e. A la par de los acuerdos, también deben fijarse formas de evaluar y medir su impacto. Esto supone una responsabilidad mayor, que supera los formalismos y protocolos de las cancillerías. También con la evaluación deben fijarse criterios para la revisión de los acuerdos; esto como proceso de retroalimentación, que permita redireccionar, fortalecer o sencillamente eliminar estrategias y puntos dentro de los acuerdos. Esta reflexión también es válida para la participación de los Estados y la ONU en misiones de paz, $\mathrm{y}$, asimismo, que los Estados, a través de sus policías, intervengan en organismos internacionales.

f. Como complemento de lo anterior, para poder evaluar se hace necesario establecer indicadores; en tal sentido, también resulta indispensable la creación o fortalecimiento de los sistemas de recolección de información estadística criminal en los países del 
continente, a la par de su creación y fortalecimiento. Como si fuera poco, también está la recomendación de estandarización para tener indicadores comunes.

\section{Agradecimientos}

A los pares evaluadores anónimos de este artículo. A los profesores del doctorado en Estudios Políticos de la Universidad Externado de Colombia, Dra. Martha Ardila, Dra. Carmen Scocoza y Dr. Graziano Palamara ya que en sus clases inicié y desarrollé las ideas de este artículo. También al Observatorio del Delito de la Policía Nacional porque en el trabajo diario se adquirió la praxis y los datos que en su mayoría sustentan este artículo. Y a los más sacrificados con mi falta de tiempo, mis padres Teresa y Juan, mi hija Gabriela y mi esposa Carolina.

JUAN APAricio Barrera

Politólogo, Especialista en Servicio de Policía, Magíster en Seguridad y Defensa Nacionales, Doctorando en Estudios Políticos. Editor Revista Criminalidad. Teniente de la Policía Nacional de Colombia, Dirección de Investigación Criminal e INTERPOL, Bogotá, D. C., Colombia.

\section{Cooperação estatal frente aos Problemas INTERMÉSTICOS. A AMEAÇA TRANSNACIONAL PENAL NA AMÉrica LATINA E O PAPEL DAS POLÍCIAS}

\section{RESUMO}

O principal problema interméstico da América Latina corresponde ao surgimento do crime com característica transnacional (atores não estáveis). Para ilustrar o problema e os atores tratarse-á dos flagelos do tráfico de drogas, medicamentos falsificados, tráfico de seres humanos, tráfico de migrantes, crime cibernético, crime ambiental, tráfico de armas de fogo, mineração ilegal, roubo de celular, falsificação de moedas, contrabando, violação de direitos autorais, roubo de carros, roubo do patrimônio cultural, corrupção e lavagem de dinheiro. Metodologia. Exercício descritivo apoiado por artigos científicos sobre o tema e dados estatísticos policiais entre os anos de 2003-2012; é um trabalho exploratório e de reflexão. Resultados. Indica-se que para enfrentar 
esses desafios os Estados recorrem à cooperação, em particular das instituições policiais, como se mostra com o caso colombiano.

Palavras-chave: Segurança. Crime transnacional. Cooperação. Polícia. Interméstico. (fonte: Tesauro de política criminal latinoamericana - Ilanud).

\section{State Cooperation against THE Intermestic Problems. The Transnational Criminal Threat in Latin America and The Role of POLICE}

\section{ABSTRACT}

The main intermestic problem in Latin America corresponds to the emergence of transnational crime (unstable actors). To illustrate the problem and the actors it will be seen the problems of drug trafficking, counterfeit drugs, human trafficking, smuggling of migrants, cybercrime, environmental crime, firearms trafficking, illegal mining, cellular theft, counterfeiting, smuggling, violation of copyrights, auto theft, cultural heritage theft, corruption and money laundering. Methodology. Descriptive exercise supported by scientific articles on the subject and police statistics between the years 2003-2012; it is an exploratory and reflective work. Results. It indicated that to face these challenges States resort to cooperation, especially the police forces as seen in the Colombian case.

KEYWORDS: Security. Transnational crimes. Cooperation. Police. Intermestic (Source: Latin American Thesaurus criminal policy - Ilanud).

\section{REFERENCIAS}

ALVARADO, I. (2012). Delincuencia organizada ambiental en México, una nueva manifestación criminal del tráfico de especies. Revista Criminalidad, 54 (1): 283-311.

APARICIO, J. (2010). De la seguridad nacional a la seguridad ciudadana: el rol de la Policía Nacional de Colombia. Bogotá: Escuela Superior de Guerra.

APARICIO, J. (2011). El fenómeno del hurto de teléfonos móviles en Colombia. Bogotá: Dirección de Investigación Criminal e Interpol, Observatorio del Delito. 
APARICIO, J. \& POVEDA, H. (2013). Apuntes de la investigación criminal de la Policía Nacional de Colombia. Nova Iustitia, I (4): 176-196.

ARDILA, M. (2013). Seminario "Dimensión Política de las Relaciones Internacionales". Bogotá, Universidad Externado de Colombia.

BATE, R. (2008, 28 de septiembre). El mundo letal de los falsos medicamentos. Esglobal, Madrid. Recuperado de: http://www. esglobal.org/el-mundo-letal-de-los-falsos-medicamentos.

BOUTROS-GHALI, G. (1992). Diplomacia preventiva, establecimiento de la paz y mantenimiento de la paz. Washington: Naciones Unidas, Asamblea General, Consejo de Seguridad.

CÁMARA de Comercio de Bogotá (2014). Balance primer semestre de 2014. Observatorio de Seguridad en Bogotá, 47.

CASAS, P. (2006). Violencia, crimen y tráfico ilegal de armas en Colombia. Bogotá: UNODC.

CASEY, J. (2010). La labor policial internacional. En: Mitchell, M. \& Casey, J. (Eds.). Conducción y administración policiales (pp. 391410). Buenos Aires: Prometeo Libros.

CLARKE, R. \& ECK, J. (s/f). Análisis delictivo para la resolución de problemas: En 60 pequeños pasos. Center for Problem-Oriented Policing - US Departament of Justice.

COLLIER, P. (2001). Causas económicas de las guerras civiles y sus implicaciones en el diseño de política. El Malpensante, 30.

CONVENCIÓN de Palermo (2000). Convención de las Naciones Unidas contra la Delincuencia Organizada. Resolución A/RES/55/25. Noviembre 15.

COOPERACIÓN Internacional de la Policía Nacional (2010). Tomo 2.5. Bogotá: Policía Nacional.

CORTÉS, Y. L. \& PARRA, R. (2011). Narcomenudeo: un neologismo para describir la venta de estupefacientes. Revista Criminalidad, 53 (2): $37-71$.

ELIAS, N. (2009). El proceso de la civilización: investigaciones sociogenéticas y psicogenéticas ( $3{ }^{a}$ ed.). México: Fondo de Cultura Económica. 
FERRAJOLI, L. (2006). Criminalidad y globalización. Boletín Mexicano de Derecho Comparado, XXXIX (115): 301-316.

GENEVA Declaration (2008). Global Burden of armed violence. Geneva.

GONZÁLEZ, P. J. (2011). Impacto espacial diferenciado en el consumo $\mathrm{y}$ adicción a las drogas en la frontera norte de México: el caso del Estado de Baja California. Revista Criminalidad, 53 (2): 15-36.

HEINE, J. \& Thakur, R. (Eds.) (2011). The dark side of globalization. New York: United Nations University Press.

ILEA (2012). ICE Derechos de Propiedad Intelectual, Lima, 6 al 10 de agosto.

INTERPOL (2014). Historia de Interpol. Recuperado de: http://www. interpol.int/es/Acerca-de-INTERPOL/Historia.

LONDOÑO, G. (2010). Una nueva era en las relaciones internacionales. Revista Policía Nacional de Colombia (282), Bogotá.

MANNING, B. (1977). The Congress, the Executive and the Intermestic Affairs: Three Proposals. Foreign Affairs, 55 (2).

MARTÍNEZ, R. (2001). La actuación policial en un contexto internacional: algunas reflexiones sobre la LPTF y la policía de UNMIK. Anuario de Derecho Internacional, XVII: 317-350.

MONJARDET, D. (2010). Lo que hace la policía. Sociología de la fuerza pública. Buenos Aires: Prometeo Libros.

MORGENTHAU, H. (1986). Una fuerza policiaca internacional. En: Política entre las naciones: la lucha por el poder y la paz $\left(3 .^{a} \mathrm{ed}.\right)$ (pp. 503-505). Buenos Aires: Grupo Editor Latinoamericano.

NEOCLEOUS, M. (2010). La fabricación del orden social. Una teoría crítica sobre el poder de policía. Buenos Aires: Prometeo Libros.

OJANGUREN, S. (2011, 17 de marzo). Las medicinas piratas amenazan la salud mundial. El Universal, México D. F. Recuperado de: http:// www.eluniversal.com.mx/columnas/88796.html.

ONU. (2014). UN Peacekeeping troop and police contributors.

Recuperado de: www.un.org/en/peacekeeping/resources/statistics/ contributors.shtml.

PNUD Guatemala (2009). La economía no observada: una aproximación 
al caso de Guatemala. Cuaderno de Desarrollo Humano, 2007/2008-4, Guatemala.

POLICÍA Nacional (2014). El equipo del Cuadrante Brasil se fortalece para apoyar la seguridad del Mundial de Fútbol Brasil 2014.

ANNP, Bogotá. Recuperado de: http://www.policia.gov.co/portal/ pls/portal/JOHN.NOTICIAS_NUEVAS_DETALLADAS. SHOW ?p_arg_names=identificador\&p_arg_values=370646.

RIORDAN, S. (2005). Adiós a la diplomacia. Madrid: Siglo XXI.

ROCHA, R. (2011). Las nuevas dimensiones del narcotráfico en Colombia. UNODC - Ministerio del Derecho y de Justicia.

ROJAS, F. (Ed.) (2000). Multilateralismo: perspectivas latinoamericanas. FLACSO-Chile, Caracas.

RUIZ, J. C., Illera, C. \& Manrique, Z. (2006). La tenue línea de la tranquilidad. Estudio comparado sobre seguridad ciudadana y policía. Bogotá: Universidad del Rosario Editorial.

RUSSELL, R. (1990). Política exterior y toma de decisiones en América Latina (pp. 255-274). Buenos Aires: RIAL.

SAIN, M. F. (2010). La reforma policial en América Latina. Una mirada crítica desde el progresismo. Buenos Aires: Prometeo Libros.

SANSÓ-RUBERT, D. (2013). La seguridad ciudadana y las Fuerzas Armadas: ¿Despropósito o último recurso frente a la delincuencia organizada? Revista Criminalidad, 55 (2): 119-133.

SMALL Arms Survey (2011). State of security. New York: Cambridge University Press.

TRANSPARENCY International. (2012). Corruption pPerceptions iIndex, 2012. Recuperado de: http://www.transparency.org/cpi2012/ results/

TICKNER, A. (2013). Cooperación por proxy. El Espectador, Bogotá. Recuperado de: http://www.elespectador.com/opinion/ cooperacion-proxy-columna- 439954.

UNIÓN Europea (2014). Oficina Europea de Policía EUROPOL. Recuperado de: http://europa.eu/abouteu/agencies/regulatory_ agencies_bodies/pol_agencies/europol/index_es.htm. 
UNODC (2011). Global Study on Homicide. Viena.

UNODC (2013). Dimensión del delito de tráfico de migrantes en

Colombia: realidades institucionales, legales y judiciales. Bogotá:

Migración Colombia - Comunidad Europea.

UNODC (2014). Delincuencia organizada transnacional: acabemos este negocio. Recuperado de: http://www.unodc.org/toc/es/crimes/ human-trafficking.html.

URREGO, D. F., Pérez L., M. C., Polanco, C. A. \& Pérez P., M. V. (2012). Control del aprovechamiento ilegal de flora a partir de la anatomía de siete especies maderables en estado de amenaza. Aporte a la política nacional ambiental. Revista Criminalidad, 54 (1):259-281.

VRANCKX, A. (Coord.) (2009). Rastreo de armas. Perspectivas sobre control, tráfico y uso de armas ilegales en Colombia. Bogotá: Universiteit Gent - Fundación Ideas para la Paz.

WEBER, M. (2007). La ciencia como profesión. La política como profesión (3. ${ }^{\mathrm{a}} \mathrm{ed}$.). Madrid: Austral.

WILSON, O., Fyfe, J., Greene, J., Walsh, W. \& Clinton, R. (1997). Administración de la policía. México: McGraw-Hill.

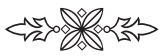

